\title{
SUBJETIVIDADES
}

Estudo Teórico

e-ISSN: 2359-0777

\section{A POLÊMICA DO TRATAMENTO PSICANALÍTICO DO AUTISMO: DIMENSÕES POLÍTICAS, SOCIAIS E ECONÔMICAS}

\author{
The Controversy of Autism Psychoanalytic Treatment: Political, Social and Economic \\ Dimensions
}

\section{La Polémica del Tratamiento Psicoanalítico del Autismo: Dimensiones Políticas, Sociales y Económicas}

\section{La Controverse du Traitement Psychanalytique de L'autisme: Dimensions Politiques, Sociales et Economiques}

DOI: $10.5020 / 23590777 . r s . v 17 i 2.5242$

\author{
Natália de Andrade de Moraes (Lattes) \\ Psicóloga. Mestranda do Programa de Pós-Graduação em Psicologia da Universidade Federal de Santa Maria.
}

\section{Claudia Maria Perrone (Lattes)}

Psicóloga e Psicanalista. Professora Associada do Curso de Psicologia e do Programa de Pós-Graduação em Psicologia da Universidade Federal de Santa Maria.

\section{Resumo}

Este estudo problematiza a polêmica do tratamento psicanalítico do autismo, situando a forma como se apresenta atualmente no Brasil. Assumindo a indissociabilidade entre os campos político e clínico, propõe a discussão dos aspectos sociopolíticos e econômicos componentes do problema como via de compreensão contextual do que se apresenta como questão clínica. Nesse sentido, trabalha sobre o modo como os avanços da lógica comportamental testemunham um apagamento da dimensão do sujeito, levando à biologização do humano e à relações de supressão da diferença e do sofrimento, discutindo os efeitos do pensamento neoliberal sobre o campo da saúde, especificamente em relação à psicanálise e ao autismo, de forma a evidenciar a submissão a uma lógica de mercado. Por fim, busca situar o lugar da psicanálise no contexto composto, sinalizando seu movimento de resistência à lógica de disputa incorporada nos debates sobre o tratamento do autismo.

Palavras-chave: psicanálise; autismo; clínica psicanalítica; psicanálise e política.

\section{Abstract}

This study problematizes the controversy of the psychoanalytic treatment of autism, situating the present form in Brazil. Assuming the inseparability between the political and clinical fields, it proposes the discussion of the socio-political and economic aspects of the problem as a way of contextual understanding of what presents itself as a clinical issue. In this sense, it works on the way in which the advances of the behavioral logic witness a erasure of the dimension of the subject, leading to the biologization of the human and the relations of suppression of the difference and the suffering, discussing the effects of neoliberal thinking on the field of health, specifically in relation to psychoanalysis and autism, in order to evidence submission to a market logic. Finally, it seeks to place the place of psychoanalysis in the composite context, signaling its movement of resistance to the logic of dispute incorporated in the debates on the treatment of autism.

Keywords: psychoanalysis; autism; psychoanalytic clinic; psychoanalysis and politics. 


\section{Resumen}

Este trabajo problematiza la polémica del tratamiento psicoanalitico del autismo, ubicando la forma como se presenta actualmente en Brasil. Asumiendo la inseparabilidad entre los campos político y clínico, propone la discusión de los aspectos sociopolíticos y económicos, piezas del problema como camino de comprensión contextual de lo que se presenta como cuestión clínica. En este sentido, trabaja sobre la forma como los avanzos de la lógica comportamental atestiguan un borrado de la dimensión del sujeto, llevando a la biologización del humano y a la relaciones de supresión de la diferencia y del sufrimiento, discutiéndolos efectos del pensamiento neoliberal sobre el campo de la salud, especificamente en relación al psicoanálisis y al autismo, de forma a evidenciar la sumisión a una lógica de mercado. Por fin, busca ubicar el sitio del psicoanálisis en el contexto compuesto, señalando su movimiento de resistencia a la lógica de lucha incorporada en los debates sobre el tratamiento del autismo.

Palabras clave: psicoanálisis; autismo; clínica psicoanalítica; psicoanálisis y política.

\section{Résumé}

Cette étude met en reliefla controverse du traitement psychanalytique de l'autism, en montrant la forme comme il se présente actuellement au Brésil. En supposant que les champs politique et clinique sont indissociables, cette étude propose la discussion des aspects sociopolitiques et économiques qui composent le problème comme manière de compréhension contextuelle de ce qui se présente comme question clinique. Dans ce sens, on travaille sur la manière comme les avances de la logique comportamentale témoignent une suppression de la dimension du sujet, ce qui mène à la biologisation de l'humain et aux relations de suppression de la différence et de la souffrance, en discutant les effets de la pensée néo-libérale sur le champ de la santé, spécifiquement en ce qui concerne la psychanalyse et l'autismo, de manière à prouver la soumission à une logique du marché. Finalement, on vise à situer la place de la psychanalyse dans le contexte composé, en sinalisant son mouvement de résistance à la logique de conflit centrée dans les discussions sur le traitement de l'autisme.

Mots-clés: psychanalyse; autisme; clinique psychanalytique; psychanalyse et politique.

Desde sua primeira conceitualização, realizada por Kanner (1943), o campo do autismo esteve marcado por intensos debates e imprecisões. Baseado na descrição detida do comportamento de onze sujeitos, o psiquiatria denominou "autistas" crianças com sérias afetações na comunicação e interação social. Fundamental para o campo da psicopatologia infantil, o trabalho de Kanner deu o passo inicial para a definição do quadro autista, abrindo espaço para uma série de novas discussões. Dentre as quais, destaca-se o debate etiológico que dividiu os teóricos em uma verdadeira disputa: psicogênese versus organogênese, vertentes radicais que representam, ainda hoje, o dualismo corpo/mente.

Comumente em relação de oposição, psicogênese e organogênese priorizam, respectivamente, a influência de aspectos psíquicos e orgânicos na etiologia do autismo. Como terceira via nesse debate, a psicanálise e as neurociências apontam à recíproca incidência entre ambos os domínios, indicando o lugar de borda ocupado pelo autismo, situado tanto nos limites da viabilidade de um sujeito quanto na borda das variantes orgânicas incidentes sobre o psiquismo (Jerusalinsky, 2013a). Para a psicanálise, processos psíquicos, neuro-maturativos e genético-ambientais associam-se de modo complexo no estabelecimento de um quadro autista, produzindo articulações múltiplas.

O pensamento reducionista, aquele que decompõe a complexidade dos fenômenos em fórmulas mais simples, resiste e intensifica-se na sociedade contemporânea. Na virada do século XX para o século XXI, o avanço do pensamento neoliberal, com ênfase na vida biológica do indivíduo e no incentivo ao consumo, e o surgimento das novas biotecnologias levaram a um processo de biologização do humano. A biologia ultrapassou seus limites tradicionais, tornando-se a referência científica hegemônica na cultura (Bezerra Jr., 2010).

Nesse novo cenário para a psicopatologia, o autismo tem ocupado lugar privilegiado, sendo tema de relevantes debates científicos e alvo de uma "guerra" que pouco diz respeito à ciência. Trata-se de uma disputa mercadológica travada entre representantes de diferentes teorias e especialidades profissionais, que mantém fraca ou nenhuma relação com a clínica, a teoria ou o campo científico que a fundamenta (Jerusalinsky, 2013a). Situa-se, portanto, como estratégia de domínio de um território e/ou objeto, extrapolando os limites do campo da saúde e lançando o autismo em uma discussão de importante alcance social.

No Brasil, pode-se demarcar a intensificação do debate público sobre o tratamento do autismo em setembro de 2012, quando a Secretaria de Estado da Saúde de São Paulo (SES/SP) publicou um edital de "Convocação para credenciamento de instituições especializadas em atendimento a pacientes com Transtorno do Espectro Autista (TEA)". A solicitação de psicólogos, por sua vez, restringia a especialidade profissional à Terapia Cognitivo-Comportamental, excluindo 
automaticamente as demais abordagens de tratamento, entre elas a psicanalítica. A essa medida seguiram-se outras similares, como o anúncio de fechamento do Instituto Centro de Referência da Infância e Adolescência (CRIA), sob justificativa de que serviços de base psicanalítica não têm eficácia comprovada (Centro de Referência da Infância e Adolescência, 2012), e a pressão exercida sobre os Centros de Atenção Psicossocial Infanto-Juvenis do estado de São Paulo para que passassem a trabalhar segundo programas terapêuticos fixos.

Percebe-se em comum nessas medidas a tentativa de interdição da psicanálise no tratamento das ditas psicopatologias graves, em especial o autismo, através da priorização de lógicas comportamentais de tratamento. Além disso, nos três casos citados, essa interdição é apoiada e possibilitada pelo Estado, chegando aos profissionais e serviços de saúde de forma verticalizada.

Por que a psicanálise precisa ser combatida? E a favor de que(m) são realizadas essas medidas? Como se sabe, a polêmica acerca do tratamento psicanalítico do autismo é mais um capítulo da guerra declarada à psicanálise desde os seus primórdios (Fendrik \& Jerusalinsky, 2011; Ferrari, 2002; Roudinesco, 2000). Ainda assim, considera-se fundamental analisar os fatores políticos e sociais que permitem que, neste momento histórico, tais medidas sejam propostas. Para tal, parte-se do pressuposto de que o campo clínico e o político, presentes nesta discussão, estão em permanente articulação, sendo a clínica diretamente afetada pelos aspectos socioculturais de uma época.

Nessa direção, busca-se apresentar a polêmica do tratamento psicanalítico do autismo no Brasil, analisando o momento de seu surgimento e intensificação. A montagem lógica do trabalho dar-se-á no sentido de (re)construir o contexto sociopolítico que permitiu a emergência das propostas de proibição do trabalho analítico com pessoas autistas.

O interesse em remontar esse cenário político e clínico, explorando as lógicas discursivas que o subjazem, conduz à discussão acerca: dos avanços da razão comportamental, com a veiculação de uma leitura cerebralista do humano; da polêmica da psicanálise no tratamento do autismo, tal como expressa na França; da polêmica dea psicanálise no tratamento do autismo em território brasileiro; da medicalização da vida e da infância, processo que desloca a problemática do autismo a um campo francamente mercadológico, voltado ao lucro; e, por fim, acerca do lugar da psicanálise nesse cenário.

\section{Sobre os avanços da lógica comportamental}

Roudinesco (2000), escrevendo em fins do século XX, aponta para uma mudança da sociedade em direção ao que chama de "a era da individualidade", que veio substituir a "era da subjetividade". Essa mudança, segundo a autora, traz consigo a ilusão de uma liberdade sem limites, de uma independência sem desejo e de uma historicidade a-histórica, transformando o homem no contrário de um sujeito. Também Barzun (2002) fala de mudança social quando remete ao avanço das neurociências nos EUA, onde a paixão pela mitologia cerebral sustenta a esperança de que as neurociências encontrem o funcionamento cerebral do psiquismo e a ilusão, construída pela farmacologia, de que seria possível encontrar o modo de funcionamento feliz.

No mesmo sentido, encontra-se a ideia, difundida pela tecnociência contemporânea, de que é possível aceder à felicidade por vias simplificadas, finalidade a que se dispõe um grande mercado: livros de autoajuda, cirurgias plásticas, listas de comportamentos adequados, e uma bateria farmacológica para empurrar a subjetividade em uma direção pré-programada (Fendrik \& Jerusalinsky, 2011), que leva à produção de uma versão pasteurizada do humano, livre da dor, da velhice e do erro.

Progressivamente, o humano passa a ser situado mais como organismo ou indivíduo, como aquele que não se divide, e menos como sujeito, sendo direcionado a buscar as respostas aos seus enigmas no exterior, ali onde o saber é legitimado pela ciência. Desse modo, recorre aos manuais diagnósticos para saber do seu sofrimento, aos fármacos para suprimi-los e a escalas numéricas para avaliar sua normalidade (ou adaptação?). Para o campo psiquiátrico, esse recurso sistemático à causalidade externa teve como consequência o deslocamento da psiquiatria dinâmica e sua substituição por um sistema comportamental. Subsiste nesse sistema o homem comportamental, interpretado por Roudinesco (2000, p.128) como "reles criatura cientificista inventada pelos adeptos do cérebro-máquina".

O que se presencia no mundo contemporâneo, estruturado pela ciência (positivista) e dirigido pela razão, é o abandono radical do sujeito que Freud valorizou. Isto porque nesse mundo parece não haver espaço para o que vem da subjetividade humana, visto que tudo precisa ser resolvido de forma rápida, limpa, eficaz e direta (Ferrari, 2002). A regra é a normatização social, fundamentada num princípio de serialização dos indivíduos via supressão das diferenças.

Seguindo pela via da normatividade, a ciência hoje se orienta pela lógica do pensamento único e ideológico. O que se acompanha não é um discurso científico preocupado com a evolução das ciências, mas a crença na determinação absoluta da capacidade da ciência. Aos discursos cientificistas, normativos, é preciso contrapor uma representação completamente diferente. Não A ciência, concebida como abstração dogmática, mas as ciências, organizadas rigorosamente, ancoradas numa história e concebidas de acordo com os modos de produção do saber (Roudinesco, 2000).

A hegemonia do ideal positivista no pensamento científico produz certas tensões nesse campo, como o que ocorre à psicanálise. Situada pelos cientificistas à margem da ciência, a psicanálise é incessantemente questionada quanto à sua teoria 
e método, sendo considerada ilegítima. No entanto, deve-se considerar a heterogeneidade dessa discussão, uma vez que o próprio conceito de ciência modifica-se segundo a perspectiva adotada. Assim, para Dunker (2013), a psicanálise pode ser considerada uma ciência desde que não se entenda ciência como sistema completo. Dessa forma, o critério de cientificidade não é o acúmulo de saber, mas a capacidade de errar, de reinterpretar e criar problemas. Roudinesco (2000) acrescenta que o critério de cientificidade de uma teoria depende tanto de sua aptidão para inventar novos modelos explicativos quanto de sua capacidade permanente de reinterpretar os modelos antigos em função de uma experiência adquirida.

A conceituação dos autores em relação à ciência contrapõe precisamente o que o cientificismo pretende produzir como totalidade: o saber como verdade. Por sua vez, a psicanálise parte do não-todo para dar conta de seus objetos de estudo/ pesquisa, situando a falta como ponto primordial na construção do saber e na busca pela verdade. Recorrendo ao autismo como exemplo, observa-se a construção a partir do equívoco e a consequente reconstrução teórico-clínica quando os analistas, hoje, assumem a hipótese etiológica da "mãe geladeira" como um grande erro (Dunker, 2013; Jerusalinsky, 2013b; Laznik, 2004).

Seguindo a discussão, Luciano Elia (2013) traz um importante debate acerca da delimitação do campo científico. $\mathrm{O}$ autor afirma que o que se apresenta hoje como ciência, sobretudo no campo que ele denomina psi (neurocientífico e comportamental, da medicina do comportamento e da psiquiatria do DSM-V), não é científico, pois toda ciência, desde Galileu, parte de um ponto de vista - uma posição simbólica - e se dirige ao real que ela pretende tornar inteligível. Para a ciência, portanto, é necessário haver um enigma, uma questão inicial que apenas depois será submetida à experiência.

A medicina do comportamento, por outro lado, estabelece uma ideia princeps e despreza toda possibilidade de que o real seja diverso daquilo que sua petição de princípio estabelece. Assim, no caso do autismo, justifica-se que há de haver uma base orgânico-cerebral para o quadro sem que tal componente tenha sido identificado. Ainda assim, o argumento é amplamente utilizado, mesmo que se situe no campo da hipótese, ou melhor, da crença. Sem revisão da ideia inicial, o que permanece é que tal componente há de existir, sem importar se o caminho metodológico fará encontrá-lo, ou não. Elia pontua, assim, que não se trata de ciência, mas de dogma, religião, mais do que de ideologia.

Faz-se importante notar o modo como os avanços do sistema comportamental, que advoga de modo absoluto sobre o que é legítimo, ou não, são mais do que uma ameaça à psicanálise, são uma ameaça ao sujeito enquanto particular e único, pois os sujeitos são afetados de modo universal pela linguagem de sua época e cada um irá encontrar sua forma particular de lidar com isso (Freitas, 2004). Se o Estado passa a legislar, por meio de medidas totalitárias sobre as possibilidades terapêuticas da pessoa de lidar com "isso", nos deparamos com um apagamento total do próprio sujeito. Cabe a ele, então, a objetivação e universalidade do discurso científico, as avaliações e perícias, os números que falam por si, sem qualquer saber ou singularidade (Perrone, 2012).

Como tal, o sujeito não pode se confundir com neurônios nem ser reduzido a um corpo. Se o termo sujeito possui sentido, a subjetividade não é mensurável ou quantificável, pois ela é a prova pela qual se afirma a essência da experiência humana (Roudinesco, 2000). Com a omissão da dimensão do sujeito, de que modo se pode situar a "experiência humana"? E, ainda mais, como se pode conceber o lugar do autismo em um sistema que ignora o que de mais particular se expressa no humano?

Os acontecimentos político-ideológicos ocorridos na França desde o início do século auxiliam na construção desse lugar e antecipam as discussões desenvolvidas atualmente no Brasil acerca do tratamento do autismo.

\section{A questão do tratamento psicanalítico do autismo na França}

No território francês, as mudanças em relação à psicanálise se fizeram notar desde o início do século. Em outubro de 2003, foi votada e aprovada a Emenda Accoyer, que visa a regulamentação do exercício das psicoterapias (Araujo et al., 2013; Harari, 2004). A emenda dispunha que as diferentes categorias de psicoterapia fossem fixadas por decreto do Ministro da Saúde e exercidas por médicos psiquiatras, ou médicos e psicólogos, com as qualificações requeridas sendo estabelecidas pelo mesmo. No caso da psicanálise, a questão tornou-se bastante problemática, pois a emenda não instituiu diferença entre a psicanálise e as psicoterapias, revelando uma pretensão de regulação da psicanálise (Harari, 2004). Além disso, não há consenso entre os psicanalistas franceses acerca das relações entre psicanálise e psicoterapias, de forma que, enquanto uns batalham pela distinção da primeira, outros se aliam às últimas.

Com o progressivo aumento no campo das psicoterapias, o fenômeno psi começou a ganhar outros contornos, influenciado pelo discurso da ciência e o discurso capitalista (Araujo et al., 2013). Ainda visando à regulação das práticas, em fevereiro de 2004 foi publicado um estudo do Instituto Nacional de Saúde e da Pesquisa Médica (Inserm), no qual três psicoterapias foram avaliadas a partir de parâmetros considerados científicos. $\mathrm{Na}$ avaliação, a psicanálise foi desqualificada e as psicoterapias cognitivo-comportamentais obtiveram lugar de destaque.

Em 2014, o Inserm publicou novo estudo, intitulado "Abordagens psicoterapêuticas do autismo. Resultados preliminares a partir de 50 estudos de caso" (Guillot, 2015). Com uma renovação no método avaliativo, pôde-se dar um novo passo em 
direção à inclusão da psicanálise no tratamento do autismo, uma vez que o estudo considerou aspectos qualitativos na elaboração dos seus resultados, a saber, os efeitos do tratamento sobre a criança e seu meio.

Ainda em relação ao autismo, destaca-se, em 1996, a aprovação da Lei Chossy pela Assembleia Nacional Francesa, que estabelece o autismo como handicap, fazendo com que não seja mais situado no grupo das doenças mentais, mas no grupo das deficiências. Como handicap específico, seria necessário ao autismo a construção de modelos particulares de tratamento a serem oferecidos pelo Estado. Hochmann (2009) diferencia os conceitos de doença e deficiência, assumindo que

uma doença (...) é um processo evolutivo, ligado a um ou mais agentes patológicos, conhecidos ou desconhecidos, que mesmo podendo ser em determinado momento considerado como incurável, pode, de fato, ter uma suposta cura em um momento onde se encontrará um remédio. Ela tem a vocação de ser tratada. Uma deficiência é um desvio fixo a uma norma, composto de um déficit e de uma incapacidade mais ou menos definidas, que deixam o sujeito em desvantagem, atrapalhando sua adaptação ao meio e podem somente ser compensadas. Ela convoca uma reabilitação, quer dizer, um reforço da utilização das capacidades restantes, o desenvolvimento de novas capacidades e uma adaptação do entorno. (Hochmann, 2009, citado por Araujo et al., 2013, p.60)

Na direção proposta pelo autor, observa-se como a questão do tratamento muda drasticamente com a aprovação da Lei Chossy. Enquanto deficiência, o tratamento do autismo deixa de ser da competência dos profissionais do campo da saúde mental (mais especificamente, psicólogos, psiquiatras e psicanalistas), passando para o campo educativo. Trata-se, então, de investir em intervenções de habilitação e reabilitação da pessoa à sua condição, considerada permanente. É importante ressaltar que se reconhece a limitação na apresentação da discussão, cujo aprofundamento escapa ao recorte aqui proposto. Na esteira dessa discussão, encontra-se a ideia de que o indivíduo "nasce e morre" autista, ou seja, de que não há perspectiva de cura.

Articulada a essa nova proposição surge, também por parte do Estado (aliado a órgãos científicos e grupos de pais), a demanda de elaboração de um documento para estabelecer diretrizes para o tratamento do autismo (Araujo et al., 2013), o qual foi publicado pela Haute Autorité de Santé (HAS), órgão responsável pelo controle da boa qualidade do sistema francês de saúde pública, em parceria com a Agência Nacional de Avaliação e da Qualidade dos Estabelecimentos e Serviços Sociais e Médico-Sociais (Anesm). O documento, intitulado Recomendações para a boa prática. Autismo e outros transtornos do desenvolvimento: intervenções educativas e terapêuticas dirigidas a crianças e adolescentes descreve as condutas a serem seguidas pelos profissionais da saúde no trabalho com a clínica do autismo.

Lançado em 2012, o documento gerou polêmica na França mesmo antes de sua publicação oficial. No jornal Libération, a questão do autismo foi destaque em reportagem intitulada "Autismo - psis foram reduzidos ao silêncio" (Perrone, 2012). No documento, fica clara a prioridade de condutas cognitivas e comportamentais na condução do tratamento de autistas em detrimento de aspectos psicopatológicos, o que levou um grupo de psicanalistas a propor uma releitura crítica do material, que não evidenciava os aspectos psicodinâmicos do quadro. Segundo publicado no Libération, o relatório afirma que "a falta de dados sobre a eficácia e a divergência de opiniões expressas permitem concluir a não pertinência das intervenções sustentadas em abordagens psicanalíticas e na psicoterapia institucional” (Perrone, 2012, p.100).

Avançando ainda mais, o deputado Daniel Fasquelle propôs um projeto de lei que visa proibir o acompanhamento psicanalítico de pessoas autistas, a favor dos métodos educacionais e comportamentais. Para ajudar as pessoas a lidar com o autismo, a França não pode continuar a tolerar e apoiar as práticas do tipo psicanalítico no tratamento do autismo. (Perrone, 2012, p.100)

Além disso, visa "o impedimento das práticas psicanalíticas no acompanhamento das pessoas autistas, a generalização dos métodos educativos e comportamentais e a realocação de todos os financiamentos existentes para esses métodos" (Araujo et al., 2013, p.68). A proposta do deputado evidencia os traços de totalitarismo presente nas estratégias do Estado na abordagem da questão do autismo e a consequente ameaça de cerceamento de liberdades individuais e coletivas (profissionais, usuários e serviços de saúde).

\section{A questão do tratamento psicanalítico do autismo no Brasil}

$\mathrm{Na}$ introdução deste trabalho, foram situadas as três principais movimentações que deflagraram a polêmica em torno do tratamento psicanalítico do autismo no Brasil: o edital de convocação da SES/SP, o anúncio de fechamento do CRIA e a pressão para que os CAPSi atendessem segundo programas terapêticos fixos (dito de outro modo, segundo a perspectiva comportamental).

Tais excessos por parte do Estado, amplamente amparados pelo discurso reducionista e por um pretenso discurso científico, encontraram resistência em um numeroso grupo de psicanalistas e profissionais vinculados à psicanálise, que 
deram forma e consistência ao Movimento Psicanálise, Autismo e Saúde Pública (MPASP). O movimento foi a público formalmente em 02 de abril de 2013, Dia Mundial de Conscientização do Autismo, com uma Carta Manifesto, que buscava evidenciar as tentativas de exclusão das práticas psicanalíticas de políticas públicas voltadas ao atendimento das pessoas autistas, ressaltando o compromisso ético de conceder aos indivíduos a opção de escolha pelo seu tratamento. Além disso, o movimento comprometeu-se com o fornecimento de informações abalizadas e responsáveis, isentas de interesses políticos e ideológicos particulares, para subsídio da definição e implantação de políticas públicas de saúde mental e, em especial, para pessoas autistas (Movimento Psicanálise, Autismo e Saúde Pública, 2013).

A atividade do MPASP e de outros órgãos e instituições, como o Conselho Regional de Psicologia de São Paulo (CRP/ SP) e o Sindicato dos Psicólogos no Estado de São Paulo (Sinpsi), possibilitou a suspensão do referido edital publicado pela SES/SP, cujo conteúdo restringia o livre exercício profissional e feria os direitos dos usuários quanto ao direito à informação e escolha sobre diferentes possibilidades terapêuticas (Conselho Regional de Psicologia de São Paulo, 2012). Na mesma direção, o fechamento do CRIA foi revogado após questionamento sobre a intervenção do Estado na questão específica do tratamento do autismo. Em vídeo-entrevista, Kufer (2013) declara considerar "problemático a SES se pronunciar sobre o que é científico ou não", apontando que a Secretaria "não possui tal mandato social e não está autorizada a fazer esse pronunciamento", referindo-se à justificativa de que as práticas de orientação psicanalítica não contam com eficácia comprovada.

Compondo o contexto especialmente crítico para a questão do autismo, em dezembro de 2012 é sancionada a Lei 12.764, que estipula que a pessoa com transtorno do espectro autista é considerada pessoa com deficiência para todos os efeitos legais. Assim como na França, a aprovação da lei foi celebrada pelas associações de pais, visto que institui a Política Nacional de Proteção dos Direitos da Pessoa com Transtorno do Espectro Autista, estabelecendo as diretrizes para sua consecução.

Posteriormente a aprovação da Lei, o governo federal deu partida a um processo público para o estabelecimento do documento "Linha de cuidado para a atenção às pessoas com transtornos do espectro do autismo na Rede de Atenção Psicossocial do Sistema Único de Saúde", o qual foi lançado em 2013 e, diferentemente do ocorrido na França, destaca a construção de projetos terapêuticos singulares no atendimento ao autismo, sem privilégio de qualquer abordagem teórica e priorizando o atendimento multidisciplinar. Segundo o documento (Ministério da Saúde, 2013), o objetivo da diretriz é oferecer orientações às equipes multiprofissionais para o cuidado à saúde da pessoa com TEA e sua família, nos diferentes pontos de atenção da Rede de Cuidados à Pessoa com Deficiência (portanto, já de acordo com a Lei 12.764).

Faz-se importante destacar ainda a veiculação da série televisiva "Autismo: Universo Particular", apresentada em televisão aberta pelo médico Dráuzio Varella. Na série, composta por quatro capítulos, foi apresentada ao público uma versão bastante reducionista do autismo, retratado como "uma doença incurável". Em termos de diagnóstico, destacou-se o saber médico, sendo omitidas informações sobre fatores de risco, intervenção precoce e trabalho interdisciplinar. Quanto ao tratamento, apenas o método comportamental foi citado.

As reações ao programa foram imediatas, sobretudo nas mídias alternativas. O MPASP (2013) elaborou uma Carta Aberta endereçada ao programa e ao médico Dráuzio Varella com o objetivo de contribuir para o esclarecimento da população, "favorecendo que programas jornalísticos e de divulgação científica possam trazer informações sérias e efetivas sobre o autismo e seu tratamento".

No contexto desta discussão, compreende-se que a série Autismo trouxe a público o núcleo do pensamento positivista, do qual o cientificismo é herdeiro. Com uma concepção normativa de ciência, o saber produzido é total, sem espaço para a dúvida ou o diálogo. O risco, nesse caso, alia-se à falta de rigor com que as informações são repassadas ao público leigo, sendo exemplar a divulgação de dados "epidêmicos" acerca dos casos de autismo no país. Tal displicência na veiculação dos dados pode levar não apenas à desinformação, como produzir sofrimento ao propor uma estratégia medicalizante na abordagem do tema.

\section{Medicalização da vida, DSM e a epidemia de autismo}

A questão do tratamento do autismo, como já mencionado, pode ser situada no contexto de resistência à psicanálise, mantidas suas peculiaridades e a importância que adquiriu na atualidade. Para além disso, pode ser igualmente situada em um contexto ainda mais amplo e que não se restringe ao que ocorre com a psicanálise: no processo de medicalização da vida humana.

Para abordar a medicalização, propõe-se a conceituação desenvolvida pelo Fórum sobre Medicalização da Infância e da Sociedade, segundo o qual "medicalização" refere-se ao processo em que as questões da vida social, sempre complexas, multifatoriais e marcadas pela cultura e pelo tempo histórico, são reduzidas à lógica médica, vinculando aquilo que não está adequado a uma norma social à uma suposta causalidade orgânica, expressa no adoecimento do indivíduo. Dessa forma, certos comportamentos e aspectos da vida humana que não são aceitos socialmente, que desviam da norma, são retirados de seus contextos, isolados dos determinantes sociais, políticos, históricos e relacionais, passando a ser compreendidos apenas como doença que deve ser tratada. 
Um exemplo bastante atual desse processo é a medicalização da infância, sobretudo no campo da educação. Para Kupfer (2011), a medicalização da infância é, atualmente, uma denúncia frequentemente associada ao modo como a indústria farmacêutica apropriou-se de certo recorte de manifestações discursivas infantis tipicamente modernas. Nesse sentido, algumas manifestações da criança são entendidas como efeitos exclusivos de disfunções neurológicas ou bioquímicas, sem nenhuma relação com aspectos psicossociais.

Ademais, o que se percebe nos processos medicalizantes é a destituição de certas figuras de suas funções, com a consequente apropriação médica. No caso da educação, os destituídos são os próprios educadores, julgados despreparados para compreender o que se passa com os alunos, assim como os pais, que passam a não saber sobre os seus filhos, visto que o saber requerido não é o construído na relação, mas um saber formal: o médico. Na clínica infantil, esse saber opera sobre os pais e a criança a partir de manuais que ditam o que deve ser feito e como (por exemplo, estabelecendo horários fixos para a sua alimentação ou ensinando aos pais a forma correta de segurar o bebê no colo). Veja-se que o problema está situado na existência de um procedimento padrão, dito correto, e que, em geral, difere ao dos pais, pois é sustentado por um saber científico que pouco lhes diz respeito.

Ressalta-se que a questão da medicalização não está necessariamente atrelada à figura do médico, mas a um discurso médico que circula pelas mais diversas esferas sociais. Na clínica psicológica, esse aspecto surge quando as crianças são apresentadas como "hiperativas" ou "deprimidas", o que evidencia uma apropriação do discurso médico pela população leiga. Considerando o modo como esse saber está inscrito e disperso no campo social, outros profissionais, como o psicólogo e o psicopedagogo, também podem ser tomados pelo discurso medicalizante em suas práticas. Nas escolas, por exemplo, é comum que o psicólogo fale de "transtornos da aprendizagem" e que o psicopedagogo "atenda" uma criança que é sua "paciente" - aqui, o próprio aluno é destituído do seu lugar (Kupfer, 2011).

Se toda manifestação infantil pode ser confundida com uma expressão sintomática, na acepção clínica do termo, é porque existe um ideal a que todas elas são equacionadas. Na rigidez da norma, a diferença torna-se desvio, ou ainda, transtorno. Essa paixão pela regra, por sua vez, é característica da condição humana neoliberal e está intimamente associada à concepção de ciência desenvolvida anteriormente, pois também aí o saber se apresenta sem falhas.

Nesse sentido, faz-se importante perceber como a rapidez e a imprecisão com que as pessoas são transformadas em "anormais" é diretamente proporcional à velocidade com que a psicofarmacologia e a psiquiatria contemporânea expandiram seu mercado (Fendrik \& Jerusalinsky, 2011). Trata-se, na verdade, de um jogo mercadológico em busca de poder: Se a neurobiologia parece afirmar que todos os distúrbios psíquicos estão ligados a uma anomalia do funcionamento das células nervosas, e já que existe o medicamento adequado, porque deveríamos nos preocupar? (Roudinesco, 2000).

Para o Estado, a lógica também é a de mercado. Com o desenvolvimento de uma abordagem liberal dos tratamentos, a clínica foi submetida a um critério de rentabilidade, sendo rentável o que traz lucro. No cenário aqui desenvolvido, o que seria o lucro? Em termos do que se espera dos indivíduos, é lucrativo para o Estado que ele (indivíduo) seja capaz de produzir, ou que esteja minimamente adaptado ao seu contexto social (como, na sala de aula escolar, um indivíduo que não incomode muito e não disperse os demais). Quanto ao custo dessas operações, ele pode ser compreendido segundo o conceito de boas práticas, outro elemento do ideário neoliberal. Boas práticas são aquelas que, em uma empresa, garantem a entrega do valor certo para o cliente com o menor custo para a organização.É uma relação de eficácia. Na saúde, são as técnicas identificadas como as melhores para realizar determinada tarefa, isto é, a forma correta de atuar com o menor custo (Perrone, 2012).

Para exemplificar, retoma-se a questão do tratamento psicanalítico. Na relação de eficácia que subjaz às boas práticas, as teses psicanalíticas passam a ser ineficazes para o Estado, pois levam a um tratamento que pode ser longo e custoso, e que, além disso, não permite a mensuração objetiva de resultados. Por outro lado, as terapêuticas farmacológicas e comportamentais tornam-se muito mais eficazes, uma vez que o tratamento é delimitado a um número específico de sessões e os resultados correspondem ao que se espera (eliminação sintomática, adaptabilidade, etc.). O que ocorre, portanto, é que, em nome do discurso científico, está-se agindo por interesses político-econômicos que nada têm a ver com promoção de saúde ou com descobertas científicas (Kupfer, 2011). Por essa razão, já não surpreende que o que foi apresentado como avanço na capacidade de curar tenha levado à ampliação progressiva da quantidade de "doentes mentais" (Fendrik \& Jerusalinsky, 2011).

Ainda assim, permanece a questão: se os avanços das neurociências e da farmacologia supostamente podem levar à cura das psicopatologias, por que as categorias diagnósticas continuam sendo ampliadas? Esta questão, recorrente no âmbito $p s i$, retornou ao debate com a publicação da quinta edição do Manual Diagnóstico e Estatístico de Transtornos Mentais (DSM-V), em 2013. Dentre outros aspectos, a publicação do Manual trouxe questionamentos acerca dos excessos na gradação dos sintomas de doenças mentais e na possível criação de uma sociedade da hiperdiagnose, na qual a normalidade torna-se um conceito cada vez mais rarefeito. Tais reflexões vêm sendo propostas inclusive por psiquiatras que, até pouco tempo, demonstravam apoio ao DSM, como Allen Frances, que aponta que sua nova edição é composta de uma mistura irresponsável de novos diagnósticos que podem estigmatizar e submeter pessoas normais a tratamentos desnecessários (Moreira, 2013).

Para Frances, existe o risco de que a criação desses novos diagnósticos exacerbe o já excessivo e inapropriado uso de medicação, especialmente em crianças. Ele lembra que, nas últimas duas décadas, a psiquiatria infantil já provocou três 
modismos: triplicou o transtorno do déficit de atenção com hiperatividade, aumentou em mais de vinte vezes o autismo e aumentou em quarenta vezes o transtorno bipolar na infância.

A criação de epidemias, entretanto, é apenas uma das consequências da redução de toda e qualquer manifestação psíquica ou psicológica a um determinismo pura e exclusivamente orgânico, que ignora qualquer causalidade psíquica. Além da criação das falsas epidemias (no caso do autismo, o aumento dos números é assustador: de 1970 a 2007, os diagnósticos saltaram de 1/25000 para 1/123 nos EUA), o apelo unicamente ao orgânico produz a medicalização da vida cotidiana, especialmente no campo infantil, e a indiferenciação de certas categorias psicopatológicas, o que produz uma série de confusões diagnósticas (Jerusalinsky, 2013b).

Como pano de fundo dessas discussões, encontram-se as maquinações da indústria farmacêutica, a qual o DSM vem representar. Se, como já mencionado, a indústria farmacêutica (que sustenta o discurso médico) é regulada pela lógica de mercado, pode-se pensar que alguns transtornos, como o autismo e o TDAH, passam a gerar muito lucro nisso que se produz como uma epidemia. De fato, o autismo se apresenta hoje como um imenso mercado, do qual psiquiatras e psicólogos comportamentais buscam se apropriar (Elia, 2013).

A explosão do número de autistas, com uma estimativa atual de 1/123 crianças nos EUA e cerca de 1/85 habitantes no Brasil, tem como ponto de partida a modificação dos critérios diagnósticos introduzida pelo DSM-IV em 1992 (Jerusalinsky, 2013b). Nessa edição do manual, foi suprimida a categoria de psicoses infantis, sendo deslocada toda sua semiologia para as categorias sindrome de Asperger e/ou transtornos invasivos do desenvolvimento e/ou espectro autista. Além disso, contribuiu para a criação da epidemia a inclusão, no critério diagnóstico, de uma série de signos, muitos deles pouco ou nada específicos, que amplia enormemente a população passível de ser inclusa na categoria de autista.

A explosão, todavia, não aparece apenas nos números. Acontece hoje que o autismo pode ser encontrado em todo lugar; seu significante começou a circular cada vez mais na cultura, nos meios de difusão, na internet e no cinema (Coriat, 2011). Nessa circulação, o que em geral se tem comunicado ao senso comum é uma visão organicista do quadro, colada a uma proposta de tratamento baseada no treinamento da criança. O risco de falar ao público geral a partir de um ponto de vista que obedece ao lobby farmacêutico é que, com a divulgação de uma semiologia confusa do quadro e uma etiologia fixa, pode-se passar a medicalizar uma parte da população que não o necessitaria (Jerusalinsky, 2013b). É preciso atentar para o cuidado em dispor informações rápidas ou resumidas para o público não especializado. Esse cuidado está relacionado à iatrogenia, à fabricação de uma doença que não existe por um falso diagnóstico positivo, situação em que se favorece a angústia familiar sem que haja necessidade para tal (Laznik, 2004).

Nos consultórios e serviços de saúde, a confusão não é menor. Como o conceito de autismo foi estendido a tal ponto que perdeu seus limites específicos, os profissionais recebem para atendimento crianças com as mais diversas questões sob o diagnóstico de autismo. Nesses casos, a problemática deve ser avaliada no um a um, mas não é irrelevante considerar o peso de tal diagnóstico sobre uma criança e seu meio, sobretudo em tempos em que o quadro está sendo intensamente associado a uma série de incapacitações e impossibilidades.

Se, apesar de todos os contras, o fenômeno do autismo continua a se produzir, é porque não se trata de uma questão de saúde nem mesmo de ciência. Dentro do balaio de gatos que se tornou a nosologia (Coriat, 2011), o que mais rapidamente escapa ao olhar é a criança/o paciente. No caso do autista, negligenciar o olhar é abandonar a clínica, uma vez que o reconhecimento do sujeito, e também do seu sofrimento, passa necessariamente pelo olhar do Outro. Sem esse primeiro olhar, pouco se pode produzir.

\section{Considerações Finais: E o Lugar da Psicanálise?}

Já foi lançada a questão: Por que a psicanálise precisa ser combatida? Talvez aqui seja possível compreendê-la. O tratamento medicamentoso pode aparecer como grande solução do sofrimento do ser, visto que prescinde até mesmo da presença humana para acontecer, gerando lucros de todas as formas. O controle das produções sintomáticas, contudo, não consegue ser assegurado e a insatisfação continua crescente (Ferrari, 2002). Se a insatisfação permanece, é porque

o efeito sujeito insiste em comparecer à cena contemporânea, porque as formações do inconsciente são produtos incansáveis e que, no mundo simbólico, ainda que advenha cada vez mais real, a linguagem continuará a ampliar o horizonte do homem à medida que retira deste sua condição de mero objeto natural, como pretende a biogenética. (Freitas, 2004, pp.38-39)

A insistência da insatisfação evidencia uma resistência à captura diagnóstica, apontando para algo da ordem do inapreensível, que surge como resto impossível de ser contido ou recoberto. Esse ponto de real, o sujeito autista o evidencia na suposta aleatoriedade de seu corpo e de seus atos. O lugar da psicanálise diferencia-se aí na possibilidade de escuta desse enigma. O aleatório como o que escapa à compreensão, mas também na própria concepção do mal-estar como inerente ao estar vivo. 
A transformação de todo mal-estar em sofrimento desvela pretensões eminentemente ideológicas ao associar-se um apelo ao consumo, à procura por objetos que, ilusoriamente, podem preencher a falta. Nesse contexto, o potencial político da psicanálise está, entre outros, na recusa das estratégias generalistas e pré-programadas de lidar com o sofrimento.

Respondendo à questão "Para que serve a psicanálise?", Maurano (2003) propõe uma bela visada à questão do malestar, ao lembrar que

(...) a psicanálise serve para percebermos a vida e o mundo pela lente da beleza do que se movimenta, do que não se aquieta.

Se isso implica um certo desassossego, uma certa falta de asseguramento, uma certa confrontação com o risco das mudanças, esse é o preço a ser pago pelo que está vivo. (p.23)

Associando o desejo à falta, o que o psicanalista propõe é um fazer com e a partir dela. Nesse sentido, a psicanálise põe em movimento um trabalho permanente de criação. É nessa direção que se pode apreendê-la enquanto dispositivo político, no sentido mais amplo da palavra: libertador, de uma potência extraordinária (Kehl, citada por Scalzo, 2010). É política porque trabalha pela liberdade (restritiva que seja) do sujeito e de sua fala; sustentando, como Freud junto às histéricas, uma dimensão ética da escuta.

No cenário atual, caso seus representantes ignorem sua história, a psicanálise corre o risco de permanecer enclausurada nas clínicas e caducar no cerne de suas próprias instituições. É de sua origem, no entanto, que seja política. Atestando um avanço da civilização sobre a barbárie, ela restaura a ideia de que o homem é livre por sua fala e de que seu destino não se restringe ao biológico. É por isso que permanece, ao lado de outras ciências, trabalhando no sentido contrário às pretensões de reduzir o pensamento a um neurônio, ou de confundir o desejo com uma secreção química (Roudinesco, 2000).

O debate acerca do tratamento do autismo vem lembrar o óbvio, isto é, que a construção da prática psicanalítica está necessariamente articulada à cultura, não estando alheia aos acontecimentos de sua época. Considerar tais articulações é compreender a existência de interesses políticos e econômicos que não apenas produzem atravessamentos importantes na prática clínica, como podem definir seus rumos.

Ressalta-se ainda que, a despeito dos ataques dos quais tem sido objeto, a psicanálise deve ser capaz de dar uma resposta humanista à selvageria de uma sociedade que tende a reduzir o homem a uma máquina desprovida de pensamento e de afeto (Roudinesco, 2000). Tais respostas têm sido elaboradas, e o Movimento Psicanálise, Autismo e Saúde Pública surge, nesse cenário, como representante de um discurso que subverte a regra de planificação dos sujeitos, resgatando a dimensão da escolha. Para isso, tem promovido um debate político e psicanalítico endereçado não apenas aos pares, mas ao social.

Comunicar à população sobre a clínica psicanalítica do autismo é dizer de um longo caminho percorrido. Caminho que não pode ser reduzido e rotulado como o de uma teoria que "culpabiliza os pais", mas o de uma teoria que, estando necessariamente articulada à clínica, permanece sendo reinventada e revista em suas concepções.

A insistência nesses debates, por sua vez, sustenta-se no desejo dos analistas em retomar o olhar sobre o sujeito autista, em oposição à lógica de disputa pelo objeto-autista. Dito de outro modo, trata-se de retomar uma discussão propriamente científica sobre o autismo, pautada no compromisso ético da psicanálise com a especificidade assumida por cada sujeito.

\section{Referências}

Araujo, G., Mrech, L. M., Saboia, C., Siqueira, T., Nezan, M., Costa, R. A., Parlato-Oliveira, E., Pires, M. L., \& Soares, M. B. (2013). Panorama das questões envolvendo psicanálise e autismo na França. Correio da APPOA - Dar a palavra aos autistas, 222/223, 55-79. Link

Barzun, J. (2002, abril). O apagão na cultura. Revista Veja, (746), 11-15. Link

Bezerra Jr., B. (2010). Neurociências e Psicanálise: Definindo discordâncias para definir o diálogo. Rev. Associação Psicanalitica de Porto Alegre, 38(1), 145-159. Link

Centro de Referência da Infância e Adolescência. (2012). Comunicado oficial da coordenação e da equipe técnica do CRIAUNIFESP diante do encerramento de suas atividades. Link

Conselho Regional de Psicologia de São Paulo[CRP SP]. (2012). CRP SP e Sinpsi se mobilizam contra edital do governo do estado de SP. São Paulo: CRP/SP. 
Coriat, E. H. (2011). Os negros efeitos do DSM-IV. In A. Jerusalinsky, \& S. Fendrik (Orgs.), O livro negro da psicopatologia contemporânea (2a ed. pp.165-174). São Paulo: Via Lettera.

Decreto de Lei nº 12.764, de 27 de dezembro de 2012. Diário Oficial da União de 28 de dezembro de 2012. Brasília: Diário Oficial da República Federativa do Brasil.

Dunker, C. I. L. (2013, 16 de Abril). Psicanálise e Ciência: Do Equívoco ao Impasse [postagem em blog]. MPASP. Link

Elia, L. (2013, 14 abril). Psicanálise, ciência e universidade [postagem em blog]. MPASP. Link

Fendrik, S., \& Jerusalinsky, A. (2011). Introdução. In A. Jerusalinsky, \& S. Fendrik (Orgs.), O livro negro da psicopatologia contemporânea ( $2^{\mathrm{a}}$ ed. pp.5-10). São Paulo: Via Lettera.

Ferrari, I. F. (2002). A psicanálise no mundo da ciência. Psicologia em Revista, 8(11), 82-91.

Freitas, I. (2004). Pode a biogenética suprimir o sujeito? In Magalhães, S. C. (Org.), O sujeito da psicanálise (pp.37-45). Salvador: Associação Científica Campo Psicanalítico.

Guillot, V. P. (2015, 7 de Fevereiro). Autismo: O Inserm valida a psicoterapia psicodinâmica. Lacan Cotidiano [Postagem em blog]. Link

Harari, A. (2004). Sobre a honra e a vergonha. In J. A. Miller, Ornicar? De Jacques Lacan a Lewis Carroll (pp.118-119). Rio de Janeiro: Jorge Zahar.

Jerusalinsky, A. (2013a). Editorial. Correio da APPOA - Dar a palavra aos autistas, 222/223, 1-3. Link

Jerusalinsky, A. (2013b). Abordagem transdisciplinar da complexidade estrutural e clínica do autismo. Correio da APPOA - Dar a palavra aos autistas, 222/223, 93-100. Link

Kanner, L. (1943). Autistic disturbances of affective contact. The Nervous Child, 2, 217-250. Link

Kupfer, M. C. M. (2011). Educação terapêutica para crianças com transtornos globais do desenvolvimento: Uma alternativa à medicalização da educação. In A. Jerusalinsky, \& S. Fendrik (Orgs.), O livro negro da psicopatologia contemporânea (a .ed. pp.141-149). São Paulo: Via Lettera.

Kupfer, M. C. M. (2013, 4 fevereiro). Entrevista: Psicanálise e autismo. Revista Brasileiros. Link

Laznik, M. C. (2004). A voz da sereia: O autismo e os impasses na constituição do sujeito. Salvador: Ágalma.

Maurano, D. (2003). Para que serve a Psicanálise? Rio de Janeiro: Jorge Zahar.

Ministério da Saúde. (2013). Diretrizes de Atenção à Reabilitação da Pessoa com Transtornos do Espectro do Autismo (TEA). Brasília: Ministério da Saúde.

Movimento Psicanálise, Autismo e Saúde Pública. (2013, 26 setembro). Carta aberta ao Fantástico e ao Dr. Dráuzio Varella sobre a série Autismo: Universo Particular [postagem em blog]. MPASP. Link

Moreira, C. A. (2013, $1^{\circ}$ de Junho). Dicionário abre discussão para separar doença e sanidade. Zero Hora - Segundo Caderno. Link

Perrone, C. M. (2012). A polêmica do autismo na França. SIG Revista de Psicanálise, 1(1), 99-102. Link

Roudinesco, E. (2000). Por que a psicanálise? Rio de Janeiro: Jorge Zahar. 
Scalzo, M. (2010). Psicanalista Política. Revista Cult. Link

\section{Endereço para correspondência}

Natália de Andrade de Moraes

Email: ntdandrade@gmail.com

Claudia Maria Perrone

Email: cmperrone@ig.com.br

Recebido em: 06/06/2016

Revisado em: 21/06/2017

Aceito em: 15/07/2017 